\title{
LA SECUENCIA ALTOMEDIEVAL DE LA IGLESIA PALEOCRISTIANA DE MARIALBA DE LA RIBERA (LEÓN)
}

\author{
Raquel MARTÍNEZ PEÑÍN
}

\begin{abstract}
RESUMEN: En este artículo nos centraremos en el análisis de la secuencia altomedieval de uno de los principales asentamientos rurales del alfoz de la ciudad de León: la iglesia paleocristiana de Marialba de la Ribera. Presentamos los resultados del estudio del material cerámico hallado durante las diferentes campañas de excavación practicada en el yacimiento, considerando tanto aspectos técnicos y morfológicos como ornamentales.
\end{abstract}

PALABRAS CLAVE: cerámica altomedieval, alfoz, León.

ABSTRACT: The aim of this communication is to show an outcome of the research carried out so far about the Early Medieval pottery in the surroundings of León city: the Early Christian church of Marialba de la Ribera. It takes into account Early Medieval pottery of the rural settlemnt from the surroundings.

KEYWORDS: Early Medieval pottery, surroundings, León.

\section{INTRODUCCIÓN}

Este trabajo tiene por objeto el estudio de la fase de ocupación altomedieval de la iglesia paleocristiana de Marialba de la Ribera, situada en el alfoz de León. En primer lugar, llevaremos a cabo una revisión de las publicaciones referidas a este yacimiento para, seguidamente, abordar el análisis del material cerámico de cronología adscrita al Alto Medievo.

Las primeras referencias a este conjunto arqueológico datan del año 1925. En esta fecha, Gómez Moreno menciona esta basílica entre los monumentos que cataloga para la provincia de León ${ }^{1}$. Años más tarde, el mismo autor publica un

\footnotetext{
${ }^{1}$ Gómez Moreno, M. (1925): Catálogo Monumental de la provincia de León. León.
} 
artículo dedicado exclusivamente al análisis artístico del edificio ${ }^{2}$ En esa misma línea vinculada a la Historia del Arte, Pedro Palol publica una serie de trabajos en los que incide en la importancia monumental del templo martirial, resaltando fundamentalmente su carácter funerario ${ }^{3}$.

Pero no será hasta finales de la década de los sesenta del pasado siglo cuando comience a cambiar el panorama de las publicaciones referidas a Marialba. En este sentido, destacan las aportaciones de Theodor Hauschild, quien, en 1968, saca a la luz los primeros resultados de las excavaciones practicadas en el yacimiento. En este trabajo se hace referencia a una parte de la cerámica altomedieval aparecida junto a las tumbas exhumadas, interpretándose como indicio de que, a lo largo de la Edad Media, la iglesia había abandonado su principal función para convertirse en necrópolis ${ }^{4}$. Posteriormente, en 1970, José Carro Otero acomete un análisis exhaustivo de los retos humanos localizados en las tumbas, tanto del ábside como de la sala, el nártex y el exterior de la basílica ${ }^{5}$. Ese mismo año, Antonio Viñayo dedica un artículo a recoger las noticias referida sal enclave basándose en la tradición oral leonesa ${ }^{6}$.

A principios de los años noventa, Jaime Rollán Ortiz lleva a cabo un estudio de tipo comparativo entre la basílica de Marialba y la de San Pedro en Veranes (Gijón), poniendo de manifiesto la problemática en torno a su estado conservación y planteando las posibilidades de una hipotética musealización ${ }^{7}$. Así mismo, en 1996, Avelino Gutiérrez González y Carmen Benéitez González publican, un artículo dedicado al análisis de la transición entre la Tardoantigüedad y la Edad Media en la provincia de León. En este trabajo también aluden al importante papel

2 Gómez Moreno (1966): "Primicias del arte cristiano español”. En: Archivo Español de Arte. Madrid, pp. 101-139.

${ }^{3}$ PALOL, P. (1967): Arqueología cristiana de la España romana. Siglos IV-VI. Valladolid; PALOL, P. (1970): Arte paleocristiano en España. Barcelona.

${ }^{4}$ Hauschild, T. (1968): "La iglesia martirial de Marialba (León)". En: Tierras de León, 9. León, pp. 21-26; HAuschiLd, T. (1970): "Excavaciones arqueológicas en la basílica paleocristiana de Marialba de la Ribera. León”. Informe inédito depositado en el Museo Arqueológico de León.

${ }^{5}$ Carro Otero, J. (1970): "Estudio anatomoantropológico de los restos humanos del templo de Marialba”. En: Legio VII Gemina. León, pp. 525-548.

${ }^{6}$ VIÑAYO, A. (1970): "Las tumbas del ábside del templo paleocristiano de Marialba, y el martirio leonés”. En: Legio VII Gemina. León, pp. 549-568.

7 ROLLÁN ORTIZ (1990): "Marialba y Veranes (Correspondencia entre dos basílicas paleocristianas)". En: Tierras de León, n 79-80. León, pp. 135-149. 
que desempeñó este enclave paradigmático en la difusión del cristianismo por tierras leonesas ${ }^{8}$.

Para finalizar, la publicación más reciente referida a la iglesia martirial de Marialba de la Ribera, corre a cargo de la arqueóloga Ma Luz González Fernández, donde recopila buena parte de los datos referidos a este conjunto arqueológico ${ }^{9}$.

Por otra parte, en el caso leonés, la mayoría del mobiliario cerámico altomedieval que conocemos procede de excavaciones realizadas en el casco urbano de León y su entorno, por lo que las continuas remociones del terreno hacen difícil la adscripción cronológica de muchos de los materiales, con la consiguiente imposibilidad de establecer cronologías relativas fiables que ayuden a su contextualización. En el caso del templo de Marialba contamos con un yacimiento en el que a penas se han producido alteraciones de este tipo, permitiéndonos establecer una seriación cronológica a partir del material arqueológico y su relación con el contexto en el que aparece.

\section{MARCO TEMPORAL}

Desde el punto de vista de las fuentes documentales, el periplo histórico de la ciudad de León ha sido ampliamente tratado por diferentes autores. Desde el ya clásico estudio de Sánchez Albornoz, pionero en estas investigaciones, otros autores -caso de Represa, Estepa, Álvarez o Gutiérrez González y Miguel Hernández-, han ido incrementado progresivamente nuestro conocimiento sobre su realidad urbana ${ }^{10}$.

${ }^{8}$ Gutiérrez González, J. A. \& Benéitez GonzÁlez, C. (1996): “Los tiempos oscuros: la transición a la Edad Media en tierras leonesas". En: Arqueoleón. León, pp. 107-122.

9 GONZÁlez FernÁndez, Ma . L. (1998): "El conjunto arqueológico de Marialba de la Ribera". En: ProMonumenta. Número II. León: 59-63.

${ }^{10}$ SÁnChez Albornoz, C. (1965): Una ciudad de la España cristiana hace mil años. Madrid.

Represa, A. (1969): "Evolución urbana de León en los siglos XI-XIII". En: Archivos Leoneses, 45y 46. León, pp. 243-282; EstePA DíEz, C. (1977): Estructura social de la ciudad de León (siglos XI-XIII). Colección "Fuentes y Estudios de Historia Leonesa". León; Álvarez Álvarez, C. (1992): La ciudad de León en la Baja Edad Media. El espacio urbano. León; ÁlvAREz ÁlvArEZ, C. (coord.) (1999): La Historia de León. Volumen II. Edad Media. León; GutiérRez GonZÁLez, J. A. \& Miguel HERNÁNDEZ, F. (1999): "Génesis del urbanismo en la ciudad de León y su tránsito a la Edad Media". En: La Península Ibérica y el Mediterráneo entre los siglos XI y XII. El urbanismo de los estados cristianos peninsulares. Palencia, pp. 45-90. 
En el año 711, la llegada de los musulmanes a la Península Ibérica, trae consigo también la incorporación de León a su ámbito de influencia. Este territorio pasa a convertirse en zona de frontera con respecto a los focos cristianos del norte. El poder islámico se limitará a desarrollar en ella una política de saqueos estacionales. Será el monarca Alfonso I (739-757) quien inicie el proceso que conduzca al fin de esta situación y logre el control administrativo de todas estas tierras, adscritas desde este momento al Reino de Asturias (718-910).

La expansión astur hacia el sur sufre un parón en el año 845, ante la presencia de tropas cordobesas en León. Sin embargo, la ciudad logrará resistir el sitio al que fue sometida. En el año 856 es ocupada por Ordoño I, quien levanta el primer Palatium en el solar de las antiguas termas romanas, reactivando de esta manera su área meridional. En estos momentos la urbe se convierte en sede diocesana, lo que facilita su crecimiento demográfico, suponiendo el inicio de un proceso que la llevará a convertirse en ciudad.

Con la muerte de Alfonso III (910) y la subida al trono de García I (910-914), León se convierte en la nueva capital del reino asturleonés. En realidad, se trata de un traslado geoestratégico desde la sede ovetense, atendiendo al avance de la línea de frontera más allá del Duero. Con este gesto la monarquía afianza el control del territorio comprendido entre la Cordillera Cantábrica y el Valle de aquel río. Este nuevo papel político desempeñado por la localidad, acelerará su proceso de trasformación urbana: en la zona sur del recinto amurallado se centralizará la actividad palatina, mientras que al este lo hará la religiosa.

En este momento la población de León se concentra al sur del recinto amurallado, en torno a la sede regia que integra la iglesia palatina de San Salvador de Palat del Rey, espacio a partir del cual la urbe seguirá expandiéndose.

El siglo XI se caracteriza por un crecimiento del número de monasterios en el interior del recinto murado, lo que conlleva el traslado del área de mayor influencia político-religiosa hacia la zona septentrional del mismo.

Así mismo, los siglos XI y XII suponen el despegue comercial y artesanal de la ciudad, lo que se traduce en una incipiente actividad constructiva. El poder real se refuerza progresivamente y tiene como consecuencia más inmediata el incremento de su control sobre la propiedad urbana. El artesanado, clase social en ascenso, en la que los francos juegan un papel fundamental, se asienta en el sector occidental 
de la muralla, concentrado en el eje de paso del Camino de Santiago o Camino Francés ${ }^{11}$.

En el siglo XII, parte de los monasterios creados en momentos anteriores, van a desaparecer para centralizarse en un reducido número de parroquias, proceso que coincide con el crecimiento de un núcleo urbano al exterior del recinto amurallado. Ese Burgo Nuevo, en estos momentos, se extiende más allá del mercado altomedieval, Mercado del Rege, constituyéndose como un espacio delimitado por un nuevo muro, de canto rodado, unido a la vieja muralla de cubos. Así, a lo largo del siglo XIII, aquellos espacios semivacíos, se van poblando de gentes. A la par, los pequeños asentamientos exteriores, -cuyos orígenes se hallan en los cenobios precedentes- comienzan a constituirse como auténticos arrabales. Todo ello constituye el inicio del despegue urbano que la ciudad de León experimenta a lo largo de la Baja Edad Media ${ }^{12}$.

Durante aquellas centurias, los núcleos rurales del alfoz experimentaron un crecimiento paralelo al de la urbe. Así lo evidencian las investigaciones desarrolladas en ámbitos como Marialba de la Ribera o Puente Castro.

\section{EL YACIMIENTO DE MARIALBA DE LA RIBERA}

A lo largo del Alto Medievo, tiene lugar en León un proceso de reaprovechamiento y adaptación de espacios. Estas evidencias ya habían sido constatadas para época tardorromana, vislumbrando la pervivencia de una reducida ocupación humana en la ciudad y su alfoz. Para la Alta Edad Media, persiste la inhabilitación de determinados sectores y la realización de hoyos. Ambos hechos, contribuyen a desvirtuar la morfología urbana de León en los momentos previos a su configuración como ciudad cristiana. No olvidemos, que a mediados del siglo IX, se erige la diócesis legionense, con circunscripción territorial propia y de carácter exento ${ }^{13}$.

A medida que se suceden las excavaciones, la información es más clara y abundante, y las características urbanas van adquiriendo cada vez mayor

11 Estepa DíEZ, C. (1977): Estructura social de la ciudad de León (siglos XI-XIII). Colección "Fuentes y Estudios de Historia Leonesa". León.

12 Álvarez Álvarez, C. (1992): La ciudad de León en la Baja Edad Media. El espacio urbano. León.

13 GonZÁlez Alonso, E. (1999): "Invasiones y época visigoda”. En: La Historia de León. Volumen I. Historia Antigua. León, pp. 325-415. 
concreción. Aún así, todavía estamos lejos de obtener una imagen completa que ofrezca una secuencia diacrónica de la evolución de la urbe y su alfoz, lo que, en definitiva, nos impide un acercamiento siquiera aproximado al paisaje urbano de la época. Ante la desvirtuación de la secuencia ocupacional del enclave urbano, hemos optado por realizar un estudio sobre la base de uno de los yacimientos altomedievales de su alfoz: la basílica paleocristiana de Marialba de la Ribera. Para tal fin, trataremos de desarrollar nuevos métodos de análisis que nos permitan superar el abismo que separa la reconstrucción histórica emprendida desde las fuentes escritas, de las investigaciones realizadas desde la arqueología.

Antes de profundizar en el análisis de la información arqueológica, es necesario presentar las características generales del yacimiento objeto de nuestro análisis. En él se ha documentado una secuencia ocupacional de alto interés para nuestro estudio y cuyos resultados bien permanecen inéditos o bien se han dado a conocer sólo de forma parcial.

La metodología aplicada al análisis del material cerámico procedente del templo de Marialba ha consistido, básicamente, en su limpieza, clasificación, siglado, inventario, sistema de registro en fichas normalizadas y documentación gráfica, para lo cual hemos desarrollado un registro individual de cada uno de los fragmentos. En este caso llevamos a cabo un estudio cualitativo, analítico y estadístico de las diversas variables discernibles en el conjunto cerámico: tipo de pasta (matriz e inclusiones), factura, cocción, decoración y tipología morfofuncional.

\section{SECUENCIA ALTOMEDIEVAL}

Esta basílica paleocristiana se localiza a unos siete kilómetros de la capital. Su ubicación puede explicarse por ser una zona bien comunicada, pues se encuentra próxima a una vía secundaria de entrada a la ciudad de León que discurre paralela al valle del río Bernesga y que estuvo en uso a lo largo de toda la Edad Media (Figs. 1 y 2$)^{14}$.

Las excavaciones practicadas en los años sesenta del siglo XX por el Instituto Alemán de Cultura, exhumaron una planta erigida con materiales constructivos propios de la tardorromanidad (aparejo de mampostería de pequeña piedra, guijarros y algún sillar, además del trabado de argamasa). A esa basílica se

14 Rabanal Alonso, M. A. (2004): "Las vías de comunicación romanas en la provincia de Zamora y León”. En: Las vías de comunicación en el noroeste ibérico. Benavente, pp. 11-34. 
asociaba una necrópolis, en uso desde la tardoantigüedad hasta la Edad Media, que se extendía por el ábside, la sala, el nártex y los espacios exteriores.

La primera fase constructiva corresponde al siglo IV: en el lado norte se abre la puerta principal, con un ancho de $3,70 \mathrm{~m}$, que da acceso a una gran sala rectangular de $23,44 \mathrm{~m}$. de longitud y 13,60 m. de anchura, muros de $0,97 \mathrm{~m}$. de grosor y suelo de cantos rodados. El extremo sur se remata con un ábside en forma de herradura, con 9,55 m. de diámetro y pared de 1,28 m. de espesor (Fig. 3).

La segunda fase constructiva ocupa los últimos años del siglo IV y principios del V. En el muro norte se erige un nártex o vestíbulo de 2,96 m. de ancho, rematado por absidiolos de herradura. Al mismo tiempo, la puerta principal se estrecha al construirse a cada lado una pilastra de 2,50 m. En esta misma fase se colocan una serie de pilastras y hornacinas en los cuatro ángulos del interior de la gran sala: los entrantes de las pilastras del lado noreste y noroeste tienen unas dimensiones de 6,61 m. de largo y 1,73 m. de profundidad. Las hornacinas del lado oeste ofrecen vanos que se corresponden con otros del muro exterior, de menor tamaño. En estos mismos momentos, en el lado este sólo se construyen estrechos nichos rectangulares. Una escalera da acceso al ábside, donde se abren tres nichos para albergar trece sepulturas. El nicho central contiene una fila con cinco, de 2,10 $\mathrm{m}$. de largo y $0,60 \mathrm{~m}$. de ancho cada una; en tanto que los laterales, paralelos a los anteriores, presentan cada uno sendas filas de cuatro tumbas (Fig. 4).

A finales del siglo VI se inicia la tercera de las fases, que se prolonga hasta principios del siglo VII: en estos momentos se levantó en el costado sureste un baptisterio, con pila de inmersión ovalada, al que se accedía por medio de dos estrechas escaleras. Presenta una planta de 1,84 m. de largo y 1,60 m. de ancho, destruida en parte por silos de almacenamiento y sepulturas de época altomedieval (Fig. 5).

Sin duda, el hecho más destacado en el Alto Medievo es la reutilización de la basílica como cementerio cristiano. Las tumbas se ubican tanto al interior como al exterior. La orientación este-oeste coincide con el rito de enterramiento cristiano. Los restos de candiles visigodos y la presencia de cerámica medieval asociadas a aquellas parece ser indicativo de que la iglesia siguió en uso a lo largo de la Edad Media (Fig. 6) ${ }^{15}$.

15 Hauschild, T. (1968): “La iglesia martirial de Marialba (León)”. En: Tierras de León, $n^{o} 9$. León, pp. 21-26. 


\section{LAS PRODUCCIONES CERÁMICAS ALTOMEDIEVALES}

El material arqueológico recuperado en la basílica paleocristiana de Marialba de la Ribera se corresponde, fundamentalmente, con restos cerámicos, acompañados de un nada despreciable conjunto de restos humanos, objetos metálicos y fauna, y, en menor medida, de otros como vidrio o elementos arquitectónicos.

En conjunto, estos materiales abarcan un segmento cronológico encuadrado entre el siglo IV y el altomedievo, lo que sin duda puede constituir un importante aporte para el conocimiento del material cerámico de este periodo en el noroeste de la Península Ibérica. Las piezas estudiadas por nosotros, sin embargo, corresponden a la fase de ocupación altomedieval.

La cerámica de adscripción medieval está documentada tanto en el interior como en el exterior de la estructura basilical. En su mayoría se halla asociada a las tumbas de este periodo.

Como rasgo generalizado, destaca su elevado índice de fragmentación, debido a los referidos procesos constructivos que provocan importantes remociones del subsuelo. No obstante, se puede afirmar que las excavaciones realizadas han proporcionado un conjunto cerámico relevante, que cuenta con ejemplos de algunas de las producciones más significativas y valoradas de la Alta Edad Media.

La vajilla recuperada está fabricada con barros silíceos bien decantados y acompañados de pequeñas inclusiones; en las producciones de grises leonesas se trata de añadidos de cuarzo, mientras que en el resto son fragmentos de caliza, arenas, etc. La mayoría de las piezas se modelan a torno lento, alternando con el urdido, con una factura descuidada, en tanto que la cocción es reductora.

Por lo que respecta al tipo de recipientes recuperados, con un repertorio bastante monótono, las formas más abundantes son las jarras y jarritas troncocónicas, de pasta gris y cocción reductora, con una o dos asas de sección circular. Son mayoritariamente de borde exvasado, labio redondeado, con diámetros de boca de entre 6 y $13 \mathrm{~cm}$. y de base de 6-11 cm, y decoración con bruñido vertical y en zigzag alternando, bien con acanaladuras, bien con molduras logradas mediante incisiones lineales paralelas (Fig. 9). Le siguen en número las ollas de pasta gris y cocción reductora, de cuerpo globular, borde exvasado, labio biselado y cuello cóncavo, con un diámetro de boca de entre $11-14 \mathrm{~cm}$. y de 10,5 a $14 \mathrm{~cm}$. en la base. Algunas de estas aparecen decoradas con incisiones a peine lineales de $2 \mathrm{~mm}$. de anchura, formando en unos casos acanaladuras horizontales y en otras ondas simples. También nos encontramos ollas en las que se repite esta misma morfología, pero con un diámetro de boca de entre $10,5-11 \mathrm{~cm}$. y $9,5 \mathrm{~cm}$. de base y 
caracterizadas por presentar decoración bruñida en zig-zag tanto en el cuello como en el galbo (Fig. 8).

Junto a estos tipos, aparecen otros ejemplos de jarras y ollas de pasta rojiza y cocción oxidante. La mayor parte de estas jarras son de tamaño mediano o grande; adoptan formas globulares con borde exvasado y, en algunos casos, con piquera de pellizco, cuello recto, labio redondeado y un diámetro de boca de entre 9 y $14 \mathrm{~cm}$ (Fig. 7). Las ollas presentan también forma globular, borde exvasado, labio biselado, cuello cóncavo al exterior, diámetro de la boca entre $11-14 \mathrm{~cm}$. y $13 \mathrm{~cm}$. de base. En algunos casos estos tipos aparecen con una ornamentación de incisiones a peine lineales formando acanaladuras horizontales de $2 \mathrm{~mm}$. de ancho.

Se constatan además cuencos envasados de pasta gris y cocción reductora, diámetros de boca de 7 a $16 \mathrm{~cm}$. y en cuya ornamentación se combina bruñido y moldura (Figs. 10 y 11).

\section{CONSIDERACIONES FINALES}

Teniendo en cuenta la información procedente de las excavaciones arqueológicas realizadas en la basílica paleocristiana de Marialba de la Ribera, además de algunas otras en la urbe leonesa, podemos apuntar que las producciones de cerámica gris leonesa, datables entre los siglos IX y X, muestran una serie de rasgos comunes indicativos de la existencia de una vajilla similar, tanto en la ciudad como en el alfoz de León para este periodo cronológico.

Entre estos lotes existen claros paralelismos técnicos, morfológicos y decorativos, aunque la variedad tipológica es más reducida en el caso de Marialba que en otros yacimientos próximos (Castro de los Judíos, Palat del Rey, etc.). Así, determinadas formas, como platos y fuentes, presentes en la ciudad y sus arrabales, están ausentes en el conjunto basilical. Esta particularidad puede deberse a que se trata de un contexto sacro y no es el espacio idóneo para que se originen depósitos de producciones con finalidad doméstica.

Este estudio nos permite establecer una seriación evolutiva de las producciones cerámicas, desde la gris leonesa, hasta la aparición de los recipientes con motivos reticulares. Por otra parte, los cambios de mobiliario cerámico los podemos observar tanto desde el punto de vista morfológico como ornamental: las jarras troncocónicas, ollas de pasta gris y cocción reductora, son progresivamente sustituidas por jarras globulares y ollas que cuentan con una mayor variedad en la morfología de los labios, bien lisas bien con decoración incisa, de cocción oxidante. 
La mayor parte de estas piezas son de tamaño medio o grande con decoración incisa, sobre todo utilizables como recipientes de cocina, mostrando en muchas ocasiones las superficies exteriores ennegrecidas por la exposición directa al fuego o como contenedores de líquido.

Los ejemplos de cerámica incisa, bien secuenciados en los siglos XI y XII, responden a los tipos habituales presentes en el resto de yacimientos estudiados en León. Aún así, en el caso de Marialba de la Ribera este tipo es menos numeroso que el de las producciones de gris leonesa, lo que puede deberse a que se trate de un motivo decorativo difundido en un momento en el que la basílica apenas está en funcionamiento.

Es sabido que este tipo de cerámica goza de un prolongado uso a lo largo del tiempo, debido a que estas piezas son, por lo general, de carácter local. La existencia de talleres de cerámicas de consumo inmediato provoca, en muchos casos, una escasa evolución formal a lo largo del tiempo, tal y como se deduce de las observaciones de este tipo de recipientes en diferentes lotes cerámicos medievales de la ciudad de León. Ese es el caso de Palat del Rey ${ }^{16}$, la plaza de Santo Martino o Puerta Castillo ${ }^{17}$, entre otros. Lo mismo sucede con otros yacimientos de la provincia: el Castro de los Judíos ${ }^{18}$, el Castillo de Valencia de don Juan ${ }^{19}$, el castillo de Alba ${ }^{20}$ y algunos más, todavía pendientes de estudio.

${ }^{16}$ Miguel Hernández, F. \& Gutiérrez GonZÁlez, J. A. (1997): "Las producciones cerámicas de León en el tránsito de la Alta a la Plena Edad Media". En: La céramique médiévale en Méditerraneé. Actes du 6 congrés, Aix-en-Provence, pp. 353-360; GutiérRez GonZÁlez, J. A. \& BENÉITEZ GONZÁLEZ, C. (1989): “Cerámica medieval en León”. En: La cerámica medieval en el norte y noroeste de la Península Ibérica. León, pp. 211-260.

${ }^{17}$ Gutiérrez GonzÁlez, J. A. \& BenÉitez GonZÁlez, C. (1989): “Cerámica medieval en León”. En: La cerámica medieval en el norte y noroeste de la Península Ibérica. León, pp. 211-260.

18 Avello Álvarez, J. \& SÁnchez-Lafuente Pérez, J. (2001): "Excavaciones en el poblado del Castro de los Judíos, Puente Castro, León. Campañas 1999-2000”. En: Lancia 4. León, pp. 221-227.

19 Gutiérrez GonzÁlez, J. A. \& BenÉitez GonzÁlez, C. (1997): “Aportaciones al repertorio cerámico bajomedieval castellano: las producciones de Valencia de don Juan". En: La céramique médiévale en Méditerraneé. Actes du 6 congrés, Aix-en-Provence, pp. 539-548.

${ }^{20}$ Gutiérrez GonzÁlez, J. A. \& BenÉITEZ GonZÁlez, C. (1989): “Cerámica medieval en León”. En: La cerámica medieval en el norte y noroeste de la Península Ibérica. León, pp. 211-260.

GonzÁlez Fernández, Ma L. \& VidAl Encinas, J. M. (2001): "El castillo de Alba no fue un castillo de naipes". En: Estudios Humanísticos, 22. León, pp. 139-156; GONZÁLEZ FERNÁNDEZ, Maa. L. \& Vidal Encinas, J. M. (2005): "El Castillo de Alba (La Robla, León): recientes trabajos 
Finalmente, este estudio nos permite plantear la hipótesis de una relación entre los cambios socioeconómicos y políticos vividos en el reino leonés en la transición de la Alta a la Baja Edad Media, y la evolución observada en los recipientes. Las piezas exhumadas en distintos contextos arqueológicos, datadas entre ambos periodos, evidencian un cambio radical en las producciones cerámicas. Tal evolución se observa tanto desde el punto de vista morfológicos como ornamental.

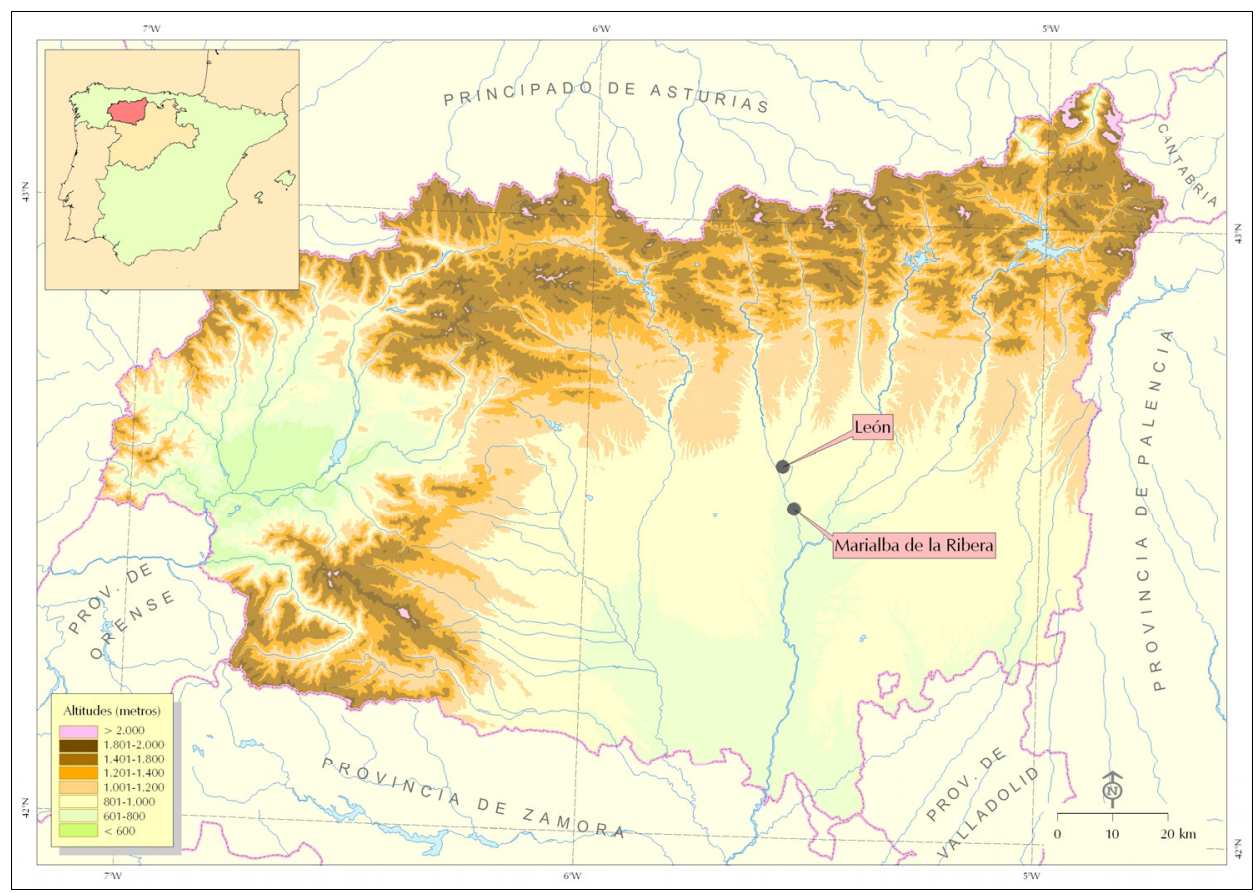

Fig. 1: Localización del yacimiento en el noroeste peninsular

arqueológicos en una fortificación de Alfonso III (866-910)". En: II Congreso de Castillología Ibérica. Madrid, pp. 585-603. 


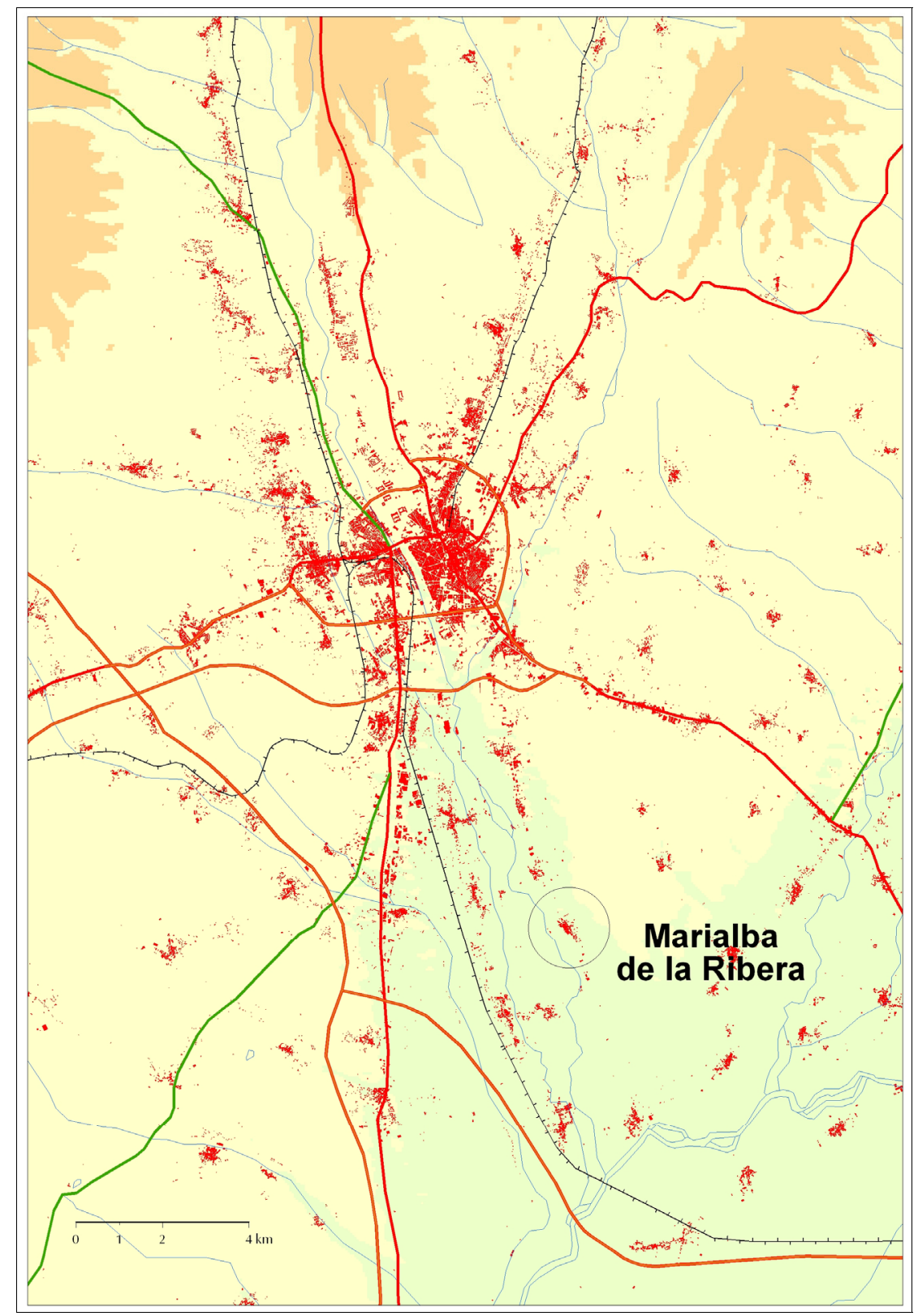

Fig. 2: La ciudad de León y la iglesia paleocristiana de Marialba de la Ribera 


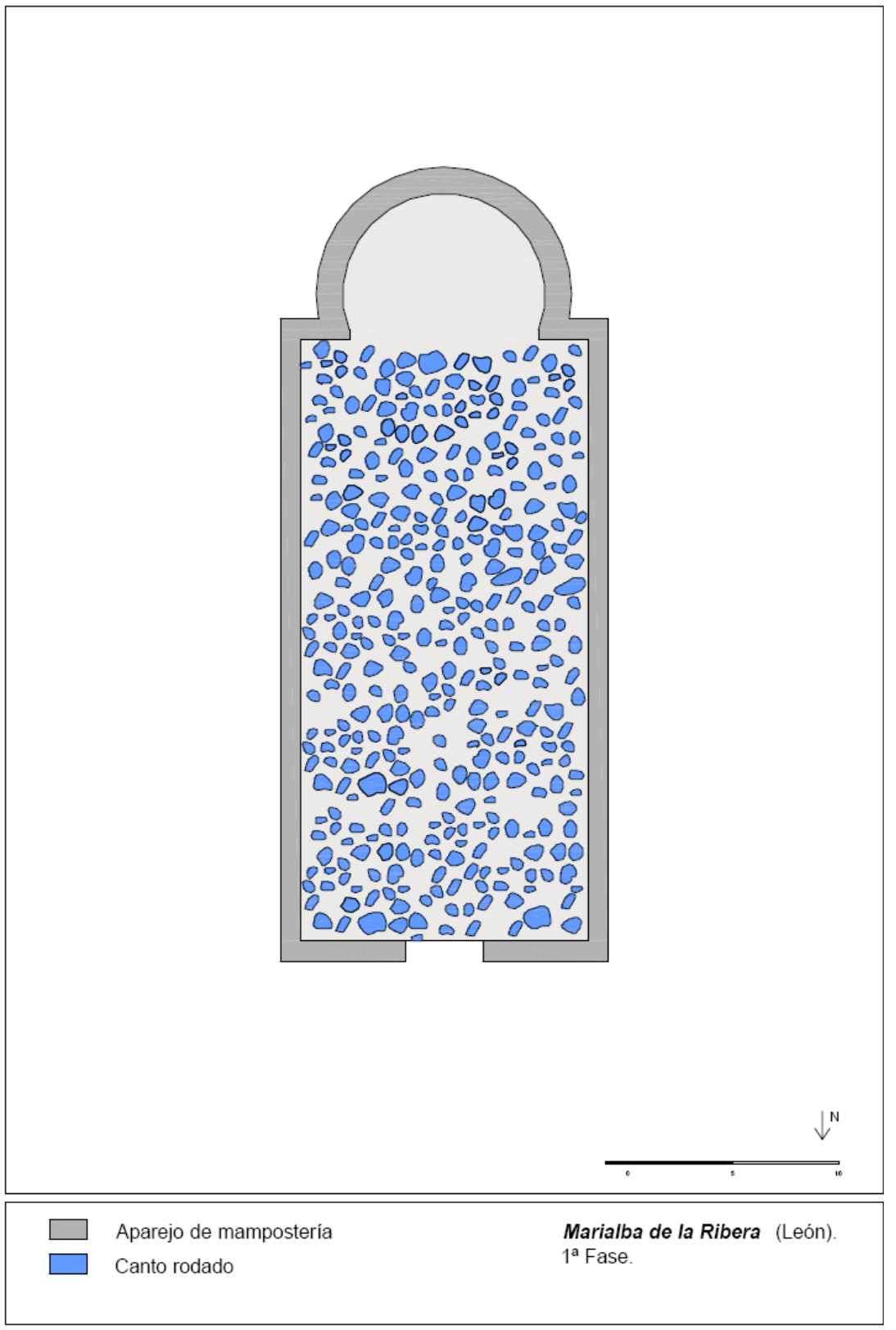

Fig. 3: Planta de la primera fase de la iglesia de Marialba de la Ribera 


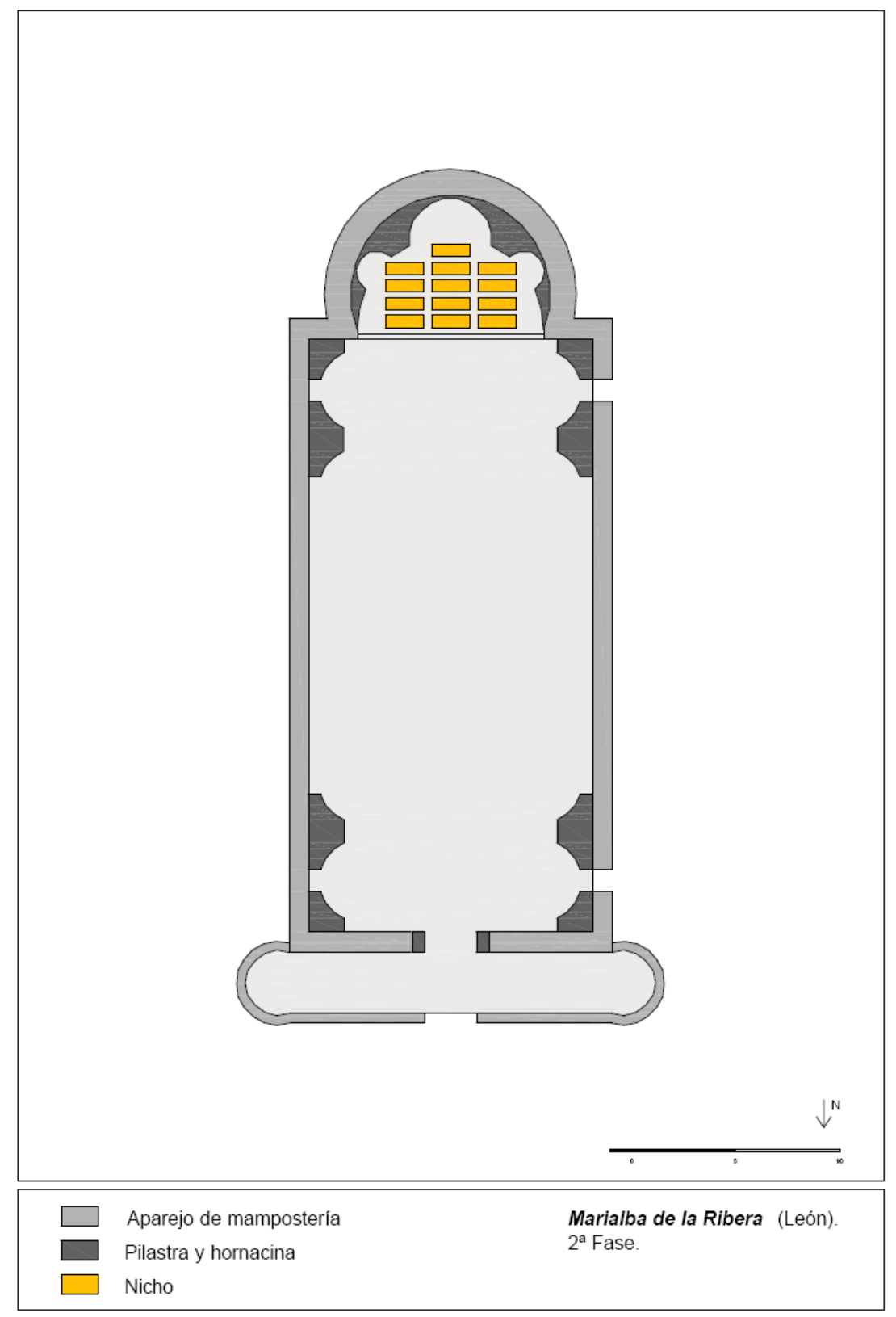

Fig. 4: Planta de la segunda fase de la iglesia de Marialba de la Ribera 


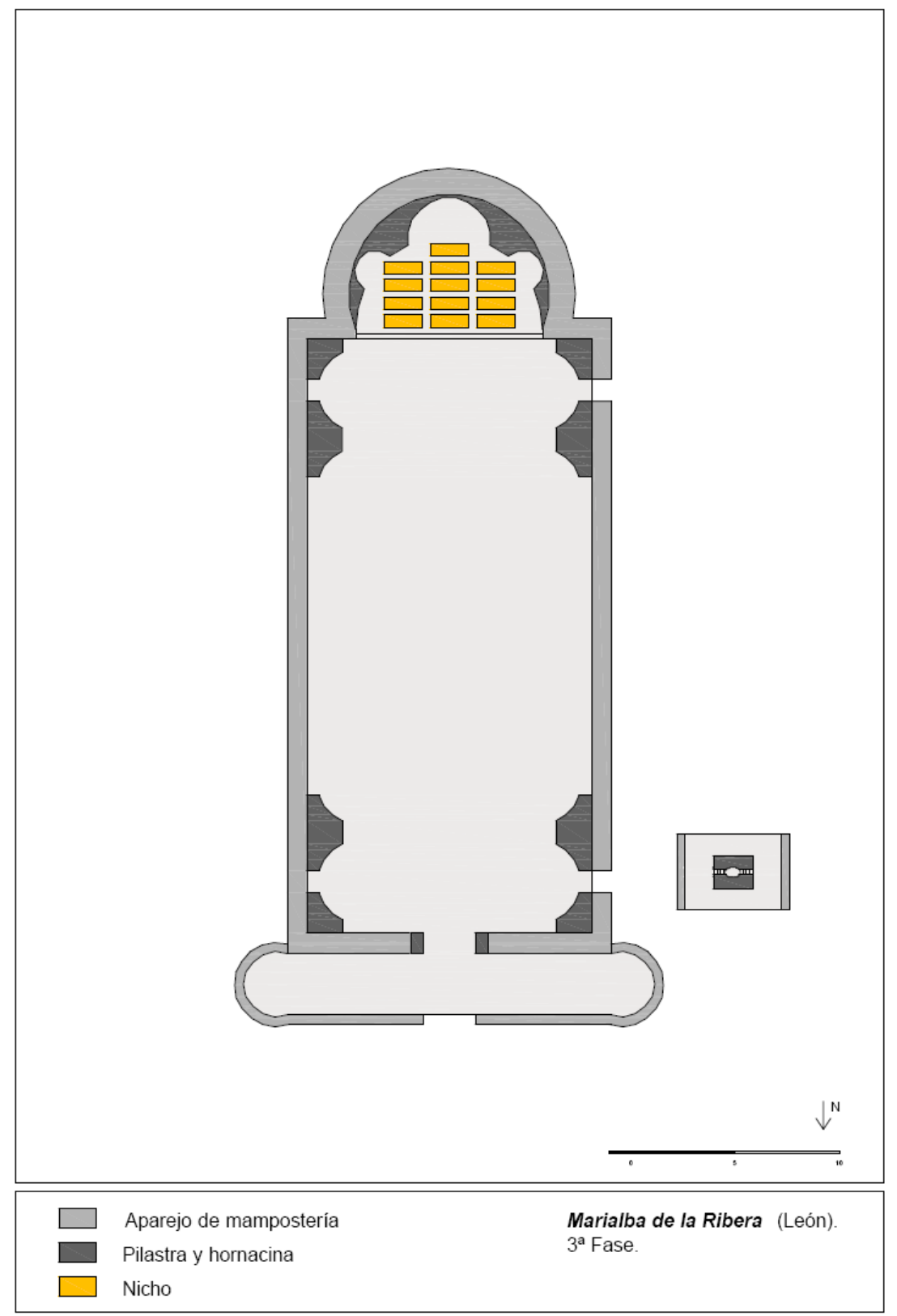

Fig. 5: Planta de la tercera fase de la iglesia de Marialba de la Ribera 


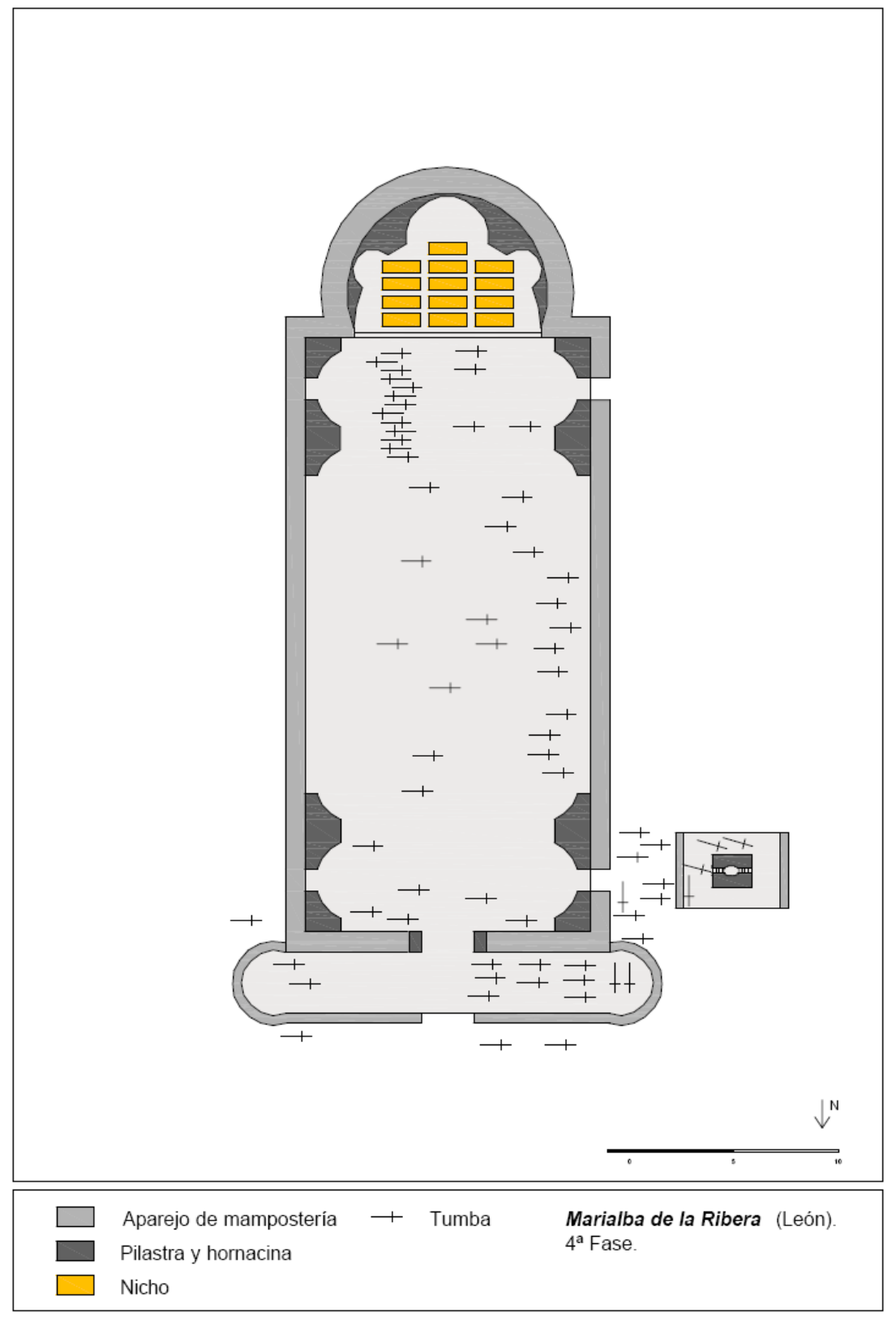

Fig. 6: Planta de la cuarta fase de la iglesia de Marialba de la Ribera 

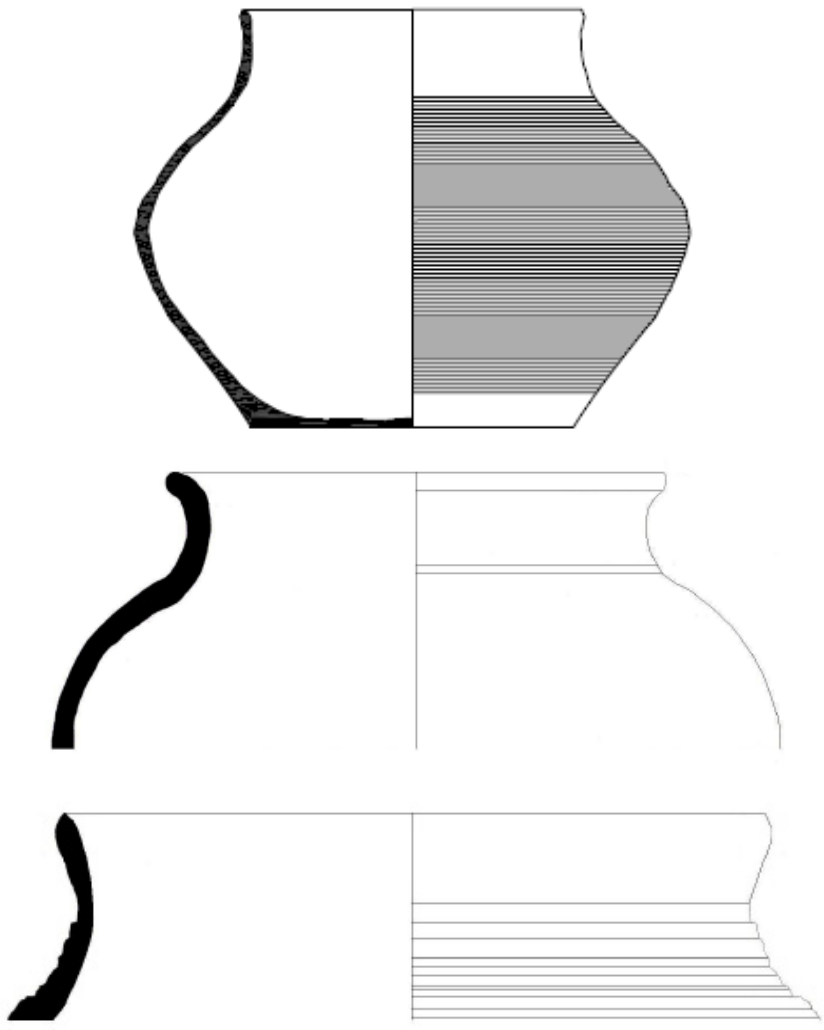

Fig. 7: Ollas con decoración incisa

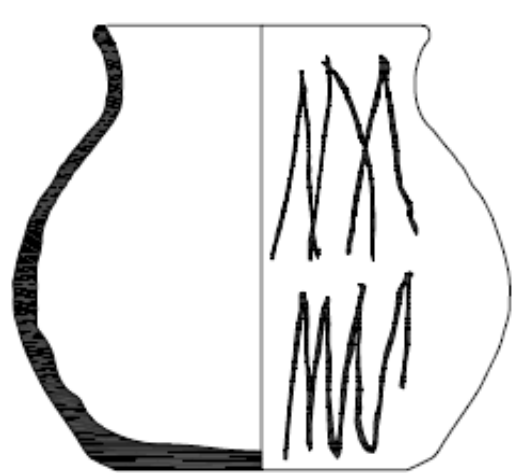

Fig. 8: Olla con decoración bruñida en zig-zag 

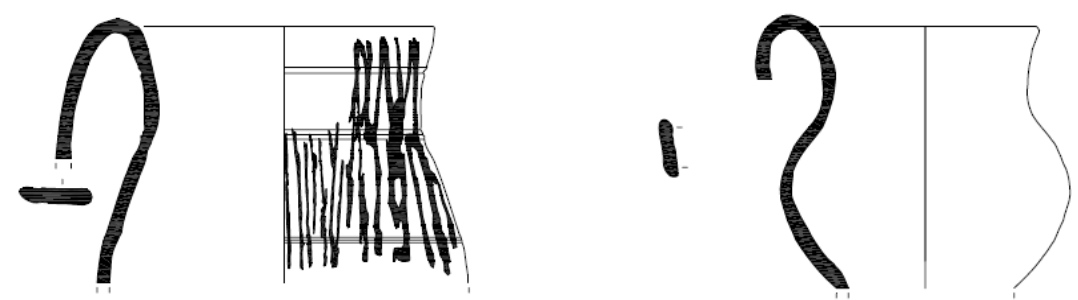

Fig. 9: Jarras de cerámica gris leonesa

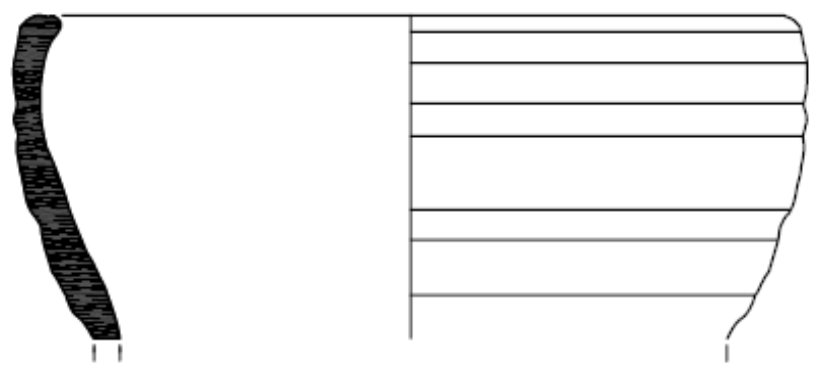

Fig. 10: Cuenco con decoración moldurada
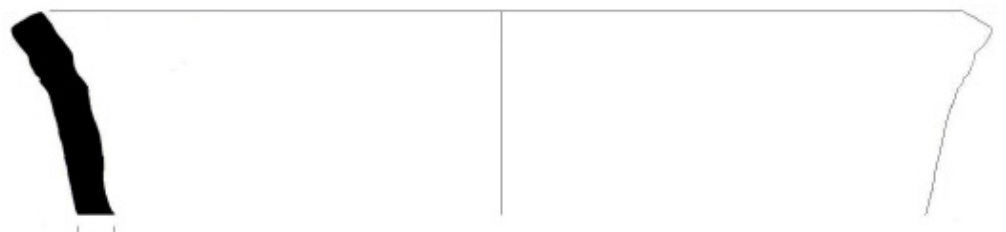

Fig. 11: Cuenco sin decorar 